\title{
Características físico-químicas e perfil lipídico do leite de cabras mestiças Moxotó alimentadas com dietas suplementadas com óleo de semente de algodão ou de girassol ${ }^{1}$
}

\author{
Marcelo Ferreira Fernandes ${ }^{2}$, Rita de Cássia Ramos do Egypto Queiroga ${ }^{3 *}$, Ariosvaldo Nunes \\ de Medeiros ${ }^{4}$, Roberto Germano Costa ${ }^{5}$, Marco Aurélio Delmondes Bomfim ${ }^{6}$, Alexandre \\ Amorim Braga ${ }^{7}$
}

\footnotetext{
${ }^{1}$ Financiado pela CAPES/CNPq.

2 Doutorando em Zootecnia - PDIZ/UFPB, Areia-PB.

${ }^{3}$ Departamento de Nutrição do CCS/UFPB.

${ }^{4}$ Departamento de Zootecnia do CCA/UFPB.

5 Departamento de Agropecuária do CFT/UFPB.

${ }^{6}$ EMBRAPA Caprinos - Sobral/CE.

7 Mestrando em Zootecnia - PPGZ/UFPB.
}

RESUMO - O efeito da suplementação com óleos de algodão e de girassol sobre a composição do leite foi testado em cabras mestiças Moxotó alimentadas com cinco dietas: controle, sem adição de óleo; adição de óleo de algodão a 3\%; óleo de algodão a 5\%; óleo de girassol a 3\%; e óleo de girassol a 5\% (\%MS). Foram utilizadas dez cabras em lactação, confinadas, distribuídas em dois quadrados latinos $(5 \times 5)$, com 12 dias de adaptação e três dias de coleta em cada período. A suplementação com óleo de algodão a 5\% MS elevou o teor de gordura $(4,99 \%)$ e de extrato seco total (13,48\%) do leite, mas não alterou a concentração dos demais componentes. A adição de 5\% de óleo de girassol, no entanto, promoveu aumento na concentração do ácido linolênico (C18:3). A adição de óleo vegetal em dietas para cabras nativas promoveu aumento do percentual de gordura no leite e aumento nos teores de ácidos graxos insaturados resultando em um produto de melhor qualidade para a saúde humana.

Palavras-chave: caprinos nativos, lipídios, óleo vegetal, semi-árido

\section{Physico-chemical characteristics and fatty acid profile of milk of crossbred Moxotó goats supplemented with cottonseed or sunflower oil}

\footnotetext{
ABSTRACT - The effects of cottonseed and sunflower oil supplementation on milk composition were tested using crossbred Moxotó goats. Experimental diets were as follows: control, without addition of oil; addition of 3\% cottonseed oil; $5 \%$ cottonseed oil; $3 \%$ sunflower oil and 5\% sunflower oil (\%DM). Ten confined lactating goats were allotted to a double Latin square experimental design $(5 \times 5)$. Each period was comprised by 12 days of adaptation to the diet and three days of sampling in each period. Cottonseed oil supplementation at $5 \% \mathrm{DM}$ increased the fat content $(4.99 \%)$ and the total solid $(13.48 \%)$ of milk. However, the addition of sunflower oil at $5 \%$ promoted an increase in the linolenic acid (C18:3) concentrations Therefore, the vegetal oil addition in diets for native goats promoted an increase in the percentage of milk fat and in unsaturated fatty acid contents in milk, resulting in a product of better quality for the human health.
}

Key Words: lipids, native goat, semi-arid, vegetable oil

\section{Introdução}

O atual enfoque do mercado aos produtos de origem animal tem sido direcionado à busca de alimentos com menores teores de gordura caracterizados como alimentos funcionais (Silva et al., 2006). A imagem nutricional da gordura do leite tem sofrido um impacto negativo nas últimas décadas, uma vez que os ácidos graxos saturados têm sido associados à elevação dos níveis séricos de colesterol e ao risco de doenças cardíacas. No entanto, além de sua contribuição energética, dependendo de sua composição em ácidos graxos, a gordura do leite pode estar potencialmente envolvida na saúde humana por ser mais digestível e por atuar na prevenção de distúrbios cardiovasculares (Chilliard et al., 2003). 
Estudos relatam a possibilidade de modificações no perfil de ácidos graxos do leite de cabra pela suplementação da dieta com fontes lipídicas (óleos, sebos, gorduras). Os óleos de algodão e de girassol são fontes de ácidos graxos poliinsaturados ricos principalmente em ácido linoléico (C18:2) que podem modificar o conteúdo de ácidos graxos da gordura do leite.

As características do leite de cabra, tanto do ponto de vista nutricional quanto social, são importantes e motivam pesquisas para avaliação da produção e da composição nutricional deste produto. No Brasil, as pesquisas ainda são insuficientes, principalmente envolvendo animais nativos; torna-se necessário, portanto, o desenvolvimento de projetos que possibilitem elucidar sua composição e sua ação nutracêutica (Queiroga \& Costa, 2004).

A suplementação lipídica para animais lactantes visa, primariamente, aumentar a concentração energética das dietas para atender à exigência no início da lactação, contudo, esta estratégia pode também contribuir para o aumento dos ácidos graxos insaturados do leite de cabra (Silva et al., 2006).

Ácidos graxos insaturados provenientes das dietas são hidrolisados no rúmen e, em seguida, passam por um processo de biohidrogenação que os converte em ácidos graxos saturados. Esse processo metabólico, no entanto, nem sempre é completo, o que resulta em uma ampla variedade de ácidos graxos insaturados (Church, 1988). Trabalhos sobre a adição de lipídios em dietas têm sido realizados quase sempre com vacas leiteiras, no entanto, são ainda incipientes aqueles realizados com cabras leiteiras (Silva et al., 2007), apesar de serem animais com processos metabólicos diferenciados (Chilliard et al., 2003).

Este estudo foi realizado com o objetivo de avaliar a influência da suplementação lipídica com óleos vegetais em diferentes níveis sobre a composição físico-química e o perfil de ácidos graxos do leite de cabras mestiças Moxotó.

\section{Material e Métodos}

O experimento foi realizado na Unidade de Pesquisa em Pequenos Ruminantes da Estação Experimental de São João do Cariri, pertencente ao Centro de Ciências Agrárias da Universidade Federal da Paraíba, em São João do Cariri, PB. O manejo dos animais foi iniciado em junho de 2005 e finalizado em março de 2006.

Foram utilizadas dez cabras mestiças Moxotó com $40,0 \pm 4,5 \mathrm{~kg}$ de peso vivo (PV), todas multíparas, aos $55 \pm 8$ dias de lactação e com características clínicas saudáveis ao início do experimento. O ensaio com as dietas experimentais teve duração de 75 dias e foi composto de cinco períodos de 15 dias. Os primeiros 12 dias de cada período foram destinados à adaptação dos animais à dieta e os outros três à coleta de amostras. Os animais foram mantidos em regime de confinamento em gaiolas para estudos de metabolismo, providas de comedouro e bebedouro, com água à vontade.

Avaliaram-se rações completas (Tabela 1) com dois tipos de óleos vegetais em dois níveis: SO - sem adição de óleo; OA-3 = adição de 3\% de óleo de algodão; OA-5 = adição de 5\% de óleo de algodão; OG-3 = adição de 3\% de

Tabela 1 - Composição das rações experimentais (\% MS)

\begin{tabular}{|c|c|c|c|c|c|}
\hline \multirow{2}{*}{$\begin{array}{l}\text { Item } \\
\text { Ingrediente }\end{array}$} & \multicolumn{5}{|c|}{ Nível de adição de óleo (\% MS) } \\
\hline & Sem adição de óleo & 3 & 5 & 3 & 5 \\
\hline Farelo de milho ${ }^{1}$ & 17,15 & 14,13 & 12,12 & 14,13 & 12,12 \\
\hline Farelo de soja & 15,05 & 15,05 & 15,06 & 15,05 & 15,06 \\
\hline Óleo de algodão & 0,00 & 2,98 & 4,99 & 0,00 & 0,00 \\
\hline Suplemento mineral & 1,50 & 1,51 & 1,51 & 1,51 & 1,51 \\
\hline Palma forrageira & 3,82 & 3,83 & 3,83 & 3,83 & 3,83 \\
\hline Feno de capim-elefante & 60,96 & 60,98 & 60,99 & 60,98 & 60,99 \\
\hline \multicolumn{6}{|l|}{ Composição nutricional } \\
\hline $\mathrm{PB}$ & 13,81 & 13,47 & 13,25 & 13,47 & 13,25 \\
\hline Volumoso:concentrado & $64: 36$ & $64: 36$ & $64: 36$ & $64: 36$ & $64: 36$ \\
\hline
\end{tabular}

${ }^{1}$ Subproduto da fabricação de flocos de milho. 
óleo de girassol; e OG-5 = adição de 5\% de óleo de girassol, com base na matéria seca (MS). A alimentação foi fornecida na forma de mistura completa, em duas refeições diárias, às 8 e $15 \mathrm{~h}$, de modo que as sobras se mantiveram em torno de $20 \%$ do oferecido, com base na ingestão do dia anterior.

O capim-elefante utilizado para a confecção do feno foi colhido quando as plantas se encontravam com 60 dias de crescimento. Após a fenação, todo o material foi triturado em máquina tipo DMP (desintegrador, moedor e picador) com peneira com perfurações de $5 \mathrm{~mm}$ e, em seguida, foi misturado aos outros ingredientes das rações experimentais. A palma utilizada era cortada com faca em tiras e fornecida aos animais.

Os óleos de algodão e de girassol usados na confecção das rações eram óleos refinados adquiridos em estabelecimentos comerciais.

As dietas foram formuladas segundo recomendações do NRC (1981) para atender às exigências nutricionais de cabras em lactação com produção de leite de $2 \mathrm{~kg} / \mathrm{cabra} /$ dia com $4 \%$ de gordura.

As cabras foram ordenhadas manualmente duas vezes ao dia ( $5 \mathrm{~h} 30$ e $16 \mathrm{~h}$ ); o controle da produção foi realizado por meio da pesagem individual do leite $(\mathrm{kg} / \mathrm{dia})$ nos três dias de coleta de cada período experimental. A amostragem de leite foi realizada duas vezes ao dia, individualmente, em frascos e vidrarias higienizados e esterilizados. Do leite coletado pela manhã retirava-se uma amostra de $180 \mathrm{~g}$ por cabra, que era armazenada em garrafas de $300 \mathrm{~mL}$ e mantida sob refrigeração a aproximadamente $5^{\circ} \mathrm{C}$ até a formação de uma amostra composta com o leite da ordenha da tarde. Em seguida, a amostra era congelada. Depois de cada período de colheita, esse leite era analisado no Laboratório de Bromatologia do Centro de Ciências da Saúde da Universidade Federal da Paraíba.

Para análise das características físicas e químicas, foram determinados os teores de proteína, utilizando-se os métodos 991.20 e 991.23 , e do extrato seco total, pelo método 925.23 da AOAC (1998). Foram empregados os métodos 433/IV; 432/IV; 437/IV; 426/IV e 423/IV do IAL (2005) para as determinações dos teores de lipídios, lactose e da acidez e densidade, respectivamente. O nitrogênio uréico no leite (NUL) foi determinado pelo método de colorimetria enzimática, utilizando-se o kit da LABTEST copyright, com leitura em espectrofotômetro.

Na identificação do perfil de ácidos graxos, uma amostra de $100 \mathrm{~mL}$ de leite referente ao terceiro dia de coleta foi centrifugada a $15.000 \times$ g por 5 minutos para separação da gordura dos demais componentes. Foram retiradas alíquotas de 0,5 $\mathrm{g}$ de gordura para a preparação dos ésteres metílicos, realizada conforme o método descrito por Hartman \& Lago (1973).

As amostras transmetiladas foram analisadas em cromatógrafo a gás modelo CG Máster, com detector de ionização de chama, coluna capilar (DB-WAX), fase estacionária polietilenoglicol (Carbowax 20M), com $30 \mathrm{~m}$ de comprimento por $0,53 \mathrm{~mm}$ de diâmetro interno e $0,25 \mathrm{~mm}$ de espessura do filme. Utilizaram-se hidrogênio como gás de arraste, vazão de $5 \mathrm{~mL} / \mathrm{min}$., nitrogênio ( $30 \mathrm{~mL} / \mathrm{min}$.) e ar sintético (300 $\mathrm{mL} / \mathrm{min}$.). O programa de temperatura do forno inicial foi de $60^{\circ} \mathrm{C}$, com graduação de $15^{\circ} \mathrm{C} / \mathrm{min}$ até $150^{\circ} \mathrm{C}$, mantida por 6 minutos. Em seguida, aumentou-se a temperatura em $4{ }^{\circ} \mathrm{C} / \mathrm{min}$ até $220^{\circ} \mathrm{C}$, mantendo-a por 10 minutos, totalizando 50 minutos. A temperatura do vaporizador foi de $210^{\circ} \mathrm{C}$ e a do detector, de $230^{\circ} \mathrm{C}$.

Uma alíquota de $2 \mu \mathrm{L}$ do extrato esterificado foi injetada no cromatógrafo e a identificação dos ácidos graxos foi feita pela comparação dos tempos de retenção dos ésteres metílicos das amostras com padrões de ácidos graxos de manteiga. As porcentagens dos ácidos graxos foram obtidas utilizando-se o software - Peaksimple (SRI Instruments - USA).

Experimentos adicionais utilizando-se uma série de padrões de alcanos com variação de C6 a C19, sob condições analíticas idênticas, foram realizados para se certificarem os índices de retenção linear dos ácidos graxos e verificar a identidade positiva dos componentes de interesse, mediante a comparação dos resultados das amostras com índices de retenção, utilizando-se a fórmula de cálculo do Índice de Retenção Linear. Quantificaram-se os ácidos graxos por normalização das áreas dos ésteres metílicos. Os resultados dos ácidos graxos foram expressos em percentual de área (\%).

O delineamento utilizado foi um quadrado latino $5 \times 5$ duplo simultâneo, constituído de dez animais, cinco dietas e cinco períodos. Os dados foram analisados no programa SAS, versão 6.2 (1996). Aplicaram-se o teste Tukey e contrastes ortogonais, ambos a 5\% de significância. Os contrastes ortogonais avaliados foram controle vs demais, óleo de algodão vs óleo de girassol e 3\% vs 5\% de óleo nas dietas. O modelo matemático utilizado na análise dos dados foi o seguinte: $\mathrm{Y}_{\mathrm{ijk}}=\mu+\mathrm{T}_{\mathrm{i}}+\mathrm{V}_{\mathrm{j}}+\mathrm{P}_{\mathrm{k}}+\varepsilon_{\mathrm{ijk}}$, em que: $\mathrm{Y}_{\mathrm{ijk}}=$ observação na cabra $\mathrm{j}$, no período $\mathrm{k}$, submetida ao tratamento $\mathrm{i} ; \mu=$ efeito geral da média geral; $\mathrm{T}_{\mathrm{i}}=$ efeito do tratamento $\mathrm{i}$, no qual $\mathrm{i}=1,2,3,4,5 ; \mathrm{V}_{\mathrm{j}}=$ efeito da cabra $\mathrm{j}$, em que $\mathrm{j}=1,2,3,4 \mathrm{e} 5 ; \mathrm{P}_{\mathrm{k}}=$ efeito do período $\mathrm{k}$, em que $\mathrm{k}=1,2$, $3,4,5$ e $\varepsilon_{\mathrm{ijk}}=$ erro aleatório associado a cada observação ijk. 


\section{Resultados e Discussão}

A adição de óleo na dieta dos animais promoveu redução na produção de leite $(\mathrm{P}<0,05)$, que foi menor quando os animais foram alimentados com a dieta com $5 \%$ de óleo de algodão $(0,970 \mathrm{~kg} / \mathrm{dia})$; no entanto, quando essa produção foi corrigida para $4 \%$ de gordura, a produção não diferiu $(\mathrm{P}>0,05)$ da obtida com a dieta controle (Figura 1).

Segundo Kronfeld (1982), a quantidade de glicose na glândula mamária é o principal fator determinante do volume de leite. O aumento da extração de ácidos graxos de cadeia longa do sangue pela glândula mamária, em decorrência de seu fornecimento no óleo da dieta, decresce a síntese de ácidos graxos de cadeias curta e média. Essa síntese requer a utilização de glicose como fornecedora de agentes redutores de NADPH, via ciclo das pentoses. Como a quantidade de ácidos de cadeia curta é pequena, ocorre diminuição na disponibilidade de glicose na glândula mamária, que pode acarretar redução na produção de leite. A utilização de gordura pode ter propiciado a diminuição na utilização da glicose (Kronfeld et al., 1980).

Mir et al. (1999) não notaram redução na produção de leite de cabras Alpinas alimentadas com dietas com até 6\% de óleo de canola. Silva et al. (2007), no entanto, registraram diferenças significativas na produção de leite quando adicionada uma fonte lipídica na dieta das cabras.

Diversos trabalhos têm demonstrado diferentes resultados de composição em gordura no leite relacionados às variações nas dietas dos animais, principalmente em trabalhos com diferentes fontes de gorduras, carboidratos solúveis e fibra (Canale et al.,1990; Palmquist, 1991; Grant
$\&$ Weidner, 1992). Segundo Duarte et al. (2005), a falta de diferença $(\mathrm{P}>0,05)$ na produção total de gordura ( $\mathrm{g} / \mathrm{dia})$ do leite pode ser decorrente do consumo de MS, que não afeta de forma negativa o ambiente ruminal pela ingestão de lipídios.

Sanz-Sampelayo et al. (2007) ressaltam que interações de forragem, concentrados e óleos da dieta estão relacionadas a variações na composição da gordura do leite, o que tem importantes implicações no perfil de ácidos graxos. Segundo os autores, o metabolismo dos lipídios na glândula mamária está diretamente relacionado à produção de leite e pode induzir respostas diferentes entre caprinos e bovinos.

Lana et al. (2005) avaliaram a adição de óleo de soja e própolis em dietas para cabras leiteiras e verificaram aumento nos teores de gordura do leite das cabras alimentadas com a dieta contendo óleo de soja, o que está de acordo com informações de Chilliard et al. (2003) de que o teor de gordura no leite de cabras aumenta com quase todos os tipos de lipídios suplementares, o que, quase sempre, não ocorre no leite de vacas.

Os resultados de composição em sólidos totais e gordura no leite encontrados nesta pesquisa estão de acordo com relatos de Pérez et al. (1996), que, em trabalho com cabras Granadinas, avaliaram a adição de gordura protegida rica em ácidos graxos poliinsaturados e verificaram aumento nos teores de sólidos totais e de gordura quando utilizaram $9 \%$ de gordura protegida na dieta desses animais.

A influência da adição de lipídios na porcentagem de gordura do leite é variável e depende de sua composição e da quantidade de gordura fornecida (NRC, 2001). Em vacas

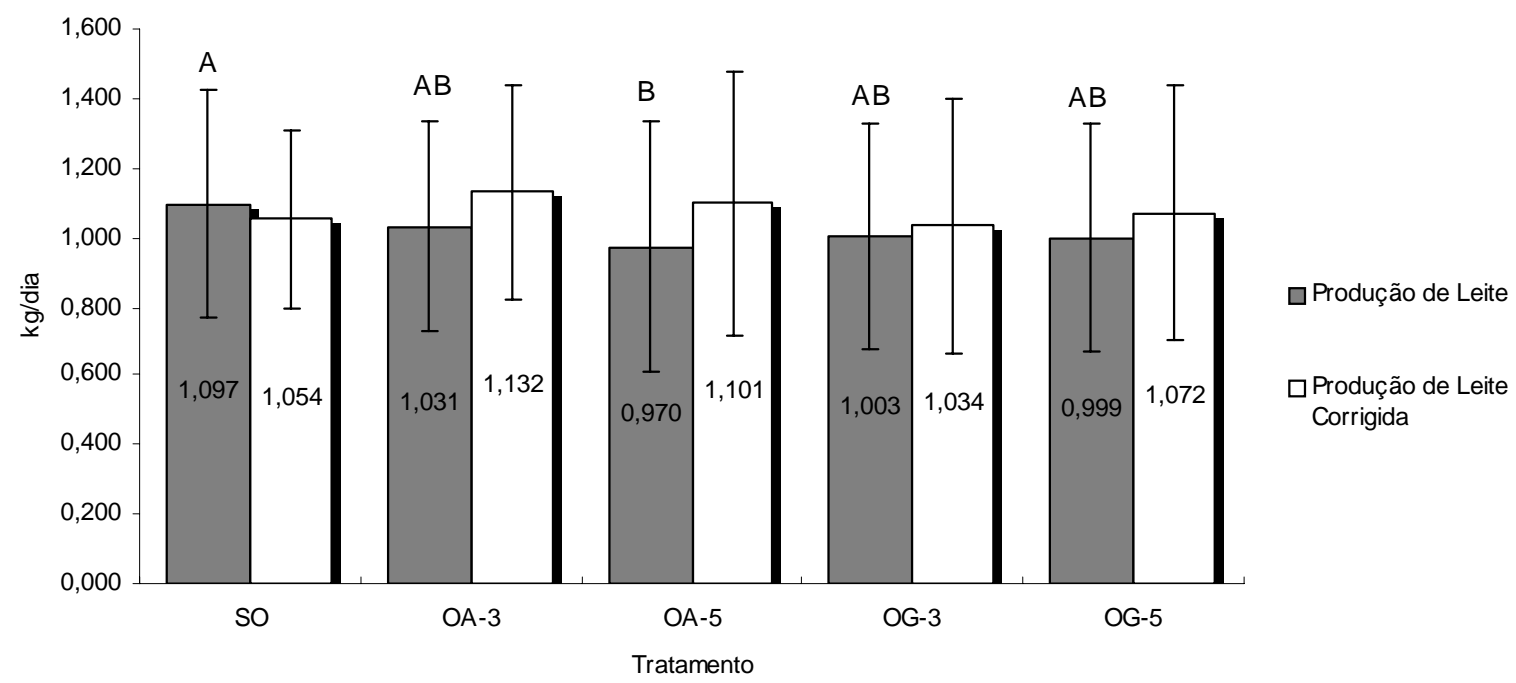

Figura 1 - Produção de leite (kg/dia) e produção de leite corrigida (4\%) em cabras mestiças Moxotó alimentadas com dietas sem adição de óleo (SO) ou com adição de óleo de algodão (OA) ou óleo de girassol (OG) nos níveis de 3 e $5 \%$. 
Tabela 2 - Produção e composição do leite de cabra mestiças Moxotó alimentadas com dietas suplementadas com óleo de algodão ou óleo de girassol

\begin{tabular}{|c|c|c|c|c|c|c|c|c|c|}
\hline \multirow[t]{3}{*}{ Característica } & \multicolumn{5}{|c|}{ Nível de adição de óleo (\% MS) } & \multirow[t]{3}{*}{$\mathrm{CV}(\%)$} & \multicolumn{3}{|c|}{ Contraste } \\
\hline & \multirow[t]{2}{*}{ Sem adição óleo } & \multicolumn{2}{|c|}{ Óleo algodão } & \multicolumn{2}{|c|}{ Óleo girassol } & & \multirow[t]{2}{*}{1} & \multirow[t]{2}{*}{2} & \multirow[t]{2}{*}{3} \\
\hline & & 3 & 5 & 3 & 5 & & & & \\
\hline Sólidos totais (\%) & $12,71 b$ & $13,16 \mathrm{ab}$ & $13,48 \mathrm{a}$ & $13,05 \mathrm{ab}$ & $13,21 \mathrm{ab}$ & 4,15 & $*$ & $\mathrm{~ns}$ & ns \\
\hline Gordura (\%) & $3,89 \mathrm{c}$ & $4,72 \mathrm{ab}$ & $4,99 \mathrm{a}$ & $4,16 b c$ & $4,48 \mathrm{abc}$ & 12,17 & $* *$ & $* *$ & ns \\
\hline Proteína (\%) & 3,23 & 3,28 & 3,42 & 3,34 & 3,37 & 6,06 & ns & $\mathrm{ns}$ & ns \\
\hline Lactose $(\%)$ & 4,20 & 4,24 & 4,30 & 4,33 & 4,36 & 3,26 & $*$ & $\mathrm{~ns}$ & ns \\
\hline Acidez $\left({ }^{\circ} \mathrm{D}\right)$ & 0,18 & 0,18 & 0,18 & 0,18 & 0,18 & 4,09 & ns & $\mathrm{ns}$ & ns \\
\hline Densidade $\left(\mathrm{g} / \mathrm{cm}^{3}\right)$ & $1.030,2$ & $1.030,1$ & $1.029,7$ & $1.029,7$ & $1.029,2$ & 0,07 & ns & $\mathrm{ns}$ & ns \\
\hline Cinzas $(\%)$ & 0,69 & 0,71 & 0,72 & 0,70 & 0,71 & 6,39 & ns & $\mathrm{ns}$ & ns \\
\hline Gordura (g/dia) & 41,00 & 47,00 & 47,00 & 42,00 & 44,00 & 12,18 & $*$ & $*$ & ns \\
\hline Proteína (g/dia) & 34,00 & 33,00 & 32,00 & 33,00 & 33,00 & 10,65 & ns & $\mathrm{ns}$ & ns \\
\hline NUL (mg/dL) & 61,98 & 59,89 & 54,50 & 57,59 & 63,96 & 19,37 & $\mathrm{~ns}$ & $\mathrm{~ns}$ & $\mathrm{~ns}$ \\
\hline
\end{tabular}

Médias seguidas de letras diferentes na mesma linha diferem a 5\% de significância pelo teste Tukey.

NUL = nitrogênio uréico no leite.

Contraste 1: controle $\times$ demais; contraste 2: algodão $\times$ girasol; contraste 3: $3 \% \times 5 \%$ de óleo.

ns: não-significativo; * $(\mathrm{P}<0,05) ;{ }^{* *}(\mathrm{P}<0,01)$.

leiteiras, a presença de ácidos graxos insaturados na dieta aumenta a probabilidade de redução na concentração de gordura do leite, uma vez que produtos intermediários da biohidrogenação, como o trans-11, podem interferir no processo de síntese de gordura do leite pela glândula mamária. Esse efeito, no entanto, não foi observado neste trabalho quando fornecida a dieta com $5 \%$ de óleo de algodão, uma vez que o leite produzido apresentou maior porcentagem de gordura. A maior taxa de passagem da digesta em cabras pode diminuir os efeitos dos suplementos lipídicos sobre os fatores ruminais que reduziriam a lipogênese na glândula mamária, aumentando o teor de gordura no leite de cabras. O teor de extrato seco total acompanhou o aumento $(\mathrm{P}<0,05)$ no teor de gordura no leite com a adição de lipídios, enquanto os demais constituintes não sofreram alterações $(\mathrm{P}>0,05)$, estando de acordo com Chilliard et al. (2003).

$\mathrm{O}$ uso de alguns tipos de gorduras suplementares tem aumentado a produção e a porcentagem de gordura do leite, mas, ao mesmo tempo, tem diminuído a porcentagem de proteína. Quando há substituição de carboidratos disponíveis por lipídios no rúmen, os lipídios têm efeito tóxico sobre os microrganismos do rúmen, causando redução no crescimento microbiano e efeito sobre o transporte de aminoácidos da glândula mamária. Assim, o conteúdo de proteína do leite pode diminuir com a deficiência de um ou mais aminoácidos (Santos et al., 2001).

Neste estudo, os teores de proteínas (Tabela 2) não foram alterados pela adição de lipídios na dieta $(\mathrm{P}>0,05)$. Segundo Wu \& Huber (1994), o efeito negativo no teor de proteína do leite por meio da suplementação lipídica seria maior em animais em início da lactação, em razão do balanço protéico negativo associado ao estado fisiológico, ou seja, há uma deficiência de aminoácidos para abastecer a alta síntese de proteína na glândula mamária. Esse processo não ocorreu neste trabalho, o que pode estar relacionado ao período de lactação em que os animais se encontravam, após o balanço negativo. Resultados de pesquisas indicam que o teor de proteína do leite de cabra não se altera em resposta à suplementação lipídica (Chilliard et al., 2003).

A diminuição no consumo de MS em vacas lactantes ocasionada pelo fornecimento de óleos vegetais tem sido observada, mas sua causa ainda não está bem estabelecida (Eifert et al., 2005). Freqüentemente, a explicação é relacionada à interferência dos lipídios insaturados sobre a atividade das bactérias Gram-positivas, principais envolvidas na fermentação da fibra (Cant et al., 1997). Entretanto, Bateman \& Jenkins (1998) comprovaram que o uso de dietas com até $8 \%$ de óleo de soja tem pouco efeito sobre a fermentação ruminal quando há adequado teor de FDN.

As concentrações de uréia no leite são consideradas bons indicadores do metabolismo e da ingestão de proteína em animais leiteiros e, atualmente, são utilizadas como ferramenta na avaliação de dietas. Os teores de uréia no leite não foram influenciados pelas dietas experimentais. Zambom et al. (2006) avaliaram a substituição do milho por casca do grão de soja em dietas para cabras Saanen e obtiveram valores médios de NUL de $17,18 \mathrm{mg} / \mathrm{dL}$ de leite. Mouro et al. (2002), no entanto, avaliaram a utilização de farinha de varredura de mandioca em dietas para cabras em lactação e encontraram valores médios de $36,87 \mathrm{mg} / \mathrm{dL}$. A uréia presente na circulação sangüínea tem a capacidade de se difundir livremente para o leite. Desse modo, é possível 
estimar a concentração de uréia no sangue medindo-se a uréia no leite, uma vez que os teores de uréia são importantes para o monitoramento da nutrição protéica em rebanhos leiteiros (Hof et al., 1997).

São escassas as pesquisas sobre a composição do leite com raças nativas no Brasil; entre os trabalhos, pode-se citar o de Laguna et al. (1998), que, avaliando a composição físico-química dos grupos genéticos $1 / 2$ Moxotó $\times 1 / 2$ PardoAlpina, $1 / 4$ Moxotó $\times 3 / 4$ Pardo-Alpina e $1 / 4$ Moxotó $\times 1 / 4$ PardoAlpina $\times 1 / 2$ Anglo-Nubiana (threecross) submetidos a um sistema semi-intensivo, verificaram que o rebanho threecross apresentou valores médios superiores em proteína, gordura e extrato seco total, a 1\% de significância, variáveis importantes a serem consideradas na elaboração de produtos derivados. Trabalhando com esses mesmos animais em regime de confinamento, Barros et al. (2005) verificaram valores de produção, de proteína, de extrato seco total e de gordura de $1,54 \mathrm{~kg} / \mathrm{dia}$ e de 3,54; $12,68 \mathrm{e}$ $3,33 \%$, respectivamente.

Araújo (2005) verificou que a utilização de diferentes níveis de feno de maniçoba em dietas para cabras Moxotó não promoveu variação na composição de leite. Os valores de proteína $(3,32 \%)$, lactose $(4,28 \%)$, extrato seco total $(13,12 \%)$ e produção de leite $(1,02 \mathrm{~kg} /$ dia $)$ encontrados neste estudo foram inferiores aos reportados por Mesquita et al. (2006), que avaliaram a composição química do leite de cabras Moxotó alimentadas com níveis crescentes de silagem de maniçoba (Manihot glaziovii Muel arg.) e não encontraram diferenças nos valores $(\mathrm{P}>0,05)$ de proteína $(3,79 \%)$, lactose $(4,66 \%)$, extrato seco total $(13,12 \%)$ e pro- dução de leite $(1,48 \mathrm{~kg} / \mathrm{dia})$. No entanto, o teor médio de gordura obtido neste trabalho foi de $4,44 \%$ vs. $3,97 \%$ encontrado por Mesquita et al. (2006), demonstrando a interferência da dieta na produção e composição dos constituintes lácteos.

As concentrações dos ácidos graxos de cadeia curta (Tabela 3), entre eles, os ácidos cáprico $\mathrm{C} 10: 0$, láurico $\mathrm{C} 12: 0$ e mirístico $\mathrm{C} 14: 0$, foram maiores $(\mathrm{P}<0,05)$ quando fornecida a dieta sem adição de óleo $(10,37 ; 5,56$ e 12,51\%, respectivamente), o que parece ser um indício de maior participação dos ácidos graxos de cadeia longa proveniente dos óleos de algodão e girassol. Essa redução pode ser decorrente da diminuição nas taxas de digestão do rúmen, em resposta à presença elevada de ácidos graxos poliinsaturados, e da conseqüente redução na produção de acetato, que pode provocar diminuição na síntese de novo na glândula mamária (Kitessa et al., 2001).

Os resultados encontrados nesta pesquisa corroboram os descritos por Maia et al. (2006), que, em pesquisa sobre a inclusão de óleos de arroz, soja e canola em dietas para cabras lactantes, verificaram redução nos ácidos graxos de cadeia curta, entre eles, o ácido láurico e o mirístico, que tornam o leite de fácil digestão, em razão da ação mais eficaz das lipases ésteres dos triglicerídeos desses ácidos graxos (Park, 1994).

Queiroga et al. (2007), avaliando diferentes manejos de cabras leiteiras, observaram variações no perfil de ácidos graxos saturados e insaturados relacionadas ao período de lactação e ao balanço energético, que implica na regulação de reservas corporais de energia e está

Tabela 3 - Perfil de ácidos graxos do leite de cabras mestiças Moxotó alimentadas com dietas suplementadas com óleo de algodão (OA) ou óleo de girassol (OG)

\begin{tabular}{|c|c|c|c|c|c|c|c|c|c|}
\hline \multirow[t]{3}{*}{ Característica } & \multicolumn{5}{|c|}{ Nível de adição de óleo (\% MS) } & \multirow[t]{3}{*}{ CV $(\%)$} & \multicolumn{3}{|c|}{ Contraste } \\
\hline & \multirow[t]{2}{*}{ Sem adição óleo } & \multicolumn{2}{|c|}{ Óleo algodão } & \multicolumn{2}{|c|}{ Óleo girassol } & & \multirow[t]{2}{*}{1} & \multirow[t]{2}{*}{2} & \multirow[t]{2}{*}{3} \\
\hline & & 3 & 5 & 3 & 5 & & & & \\
\hline C $6: 0$ & 1,35 & 1,14 & 0,99 & 1,19 & 1,95 & 47,71 & ns & ns & ns \\
\hline C $8: 0$ & 3,05 & 2,27 & 2,04 & 2,33 & 2,88 & 24,40 & $*$ & ns & ns \\
\hline C 10:0 & $10,37 \mathrm{a}$ & $7,48 \mathrm{ab}$ & $6,17 b$ & $7,74 \mathrm{ab}$ & $7,59 \mathrm{ab}$ & 21,68 & $* *$ & ns & $\mathrm{ns}$ \\
\hline C $12: 0$ & $5,56 a$ & $2,99 b$ & $2,59 b$ & $3,33 b$ & $3,59 \mathrm{~b}$ & 24,77 & $* * *$ & ns & ns \\
\hline C $14: 0$ & $12,51 \mathrm{a}$ & $8,05 b$ & $6,81 b$ & $8,32 \mathrm{ab}$ & $8,36 \mathrm{~b}$ & 16,29 & $* * *$ & ns & ns \\
\hline C $16: 0$ & $24,85 \mathrm{ab}$ & $25,40 \mathrm{ab}$ & $29,12 \mathrm{a}$ & $19,47 \mathrm{ab}$ & $18,54 \mathrm{~b}$ & 22,89 & ns & $* *$ & ns \\
\hline C $16: 1$ & 1,96 & 1,36 & 2,00 & 1,59 & 1,96 & 40,93 & ns & ns & ns \\
\hline C $18: 0$ & 11,64 & 14,78 & 15,02 & 18,29 & 17,96 & 30,24 & $*$ & $\mathrm{~ns}$ & ns \\
\hline C $18: 1$ & $25,28 b$ & $31,14 \mathrm{ab}$ & $28,29 \mathrm{ab}$ & $31,96 \mathrm{a}$ & $29,25 \mathrm{ab}$ & 11,91 & $* *$ & ns & ns \\
\hline C $18: 2$ & 2,43 & 3,46 & 3,56 & 3,18 & 3,77 & 28,94 & $*$ & ns & ns \\
\hline C $18: 3$ & $1,55 b$ & $2,38 b$ & $2,68 b$ & $2,89 \mathrm{~b}$ & $5,32 \mathrm{a}$ & 35,16 & $* *$ & $* *$ & $* *$ \\
\hline (C 6:0-C 14:0) & $31,49 \mathrm{a}$ & $20,80 \mathrm{~b}$ & $17,62 b$ & $21,72 b$ & $22,42 b$ & 17,98 & $* * *$ & ns & $\mathrm{ns}$ \\
\hline Insaturados & $29,25 b$ & $36,98 \mathrm{a}$ & $34,54 \mathrm{ab}$ & $38,02 \mathrm{a}$ & $38,34 \mathrm{a}$ & 10,47 & $* * *$ & ns & ns \\
\hline IA & $2,77 \mathrm{a}$ & $1,67 b$ & $1,79 b$ & $1,48 b$ & $1,45 b$ & 22,13 & $* * *$ & ns & ns \\
\hline
\end{tabular}

Médias seguidas de letras diferentes na mesma linha diferem a 5\% de significância pelo teste Tukey.

$\mathrm{IA}=$ Índice de Aterogenecidade (C12 + 4 C14 + C16):(soma dos insaturados)

Contraste 1: controle $\times$ demais; contraste 2: algodão $\times$ girassol; contraste 3: $3 \% \times 5 \%$ de óleo.

ns: não-significativo; * $(\mathrm{P}<0,05) ;{ }^{* *}(\mathrm{P}<0,01)$. 
diretamente associado ao aporte de ácidos graxos de cadeia longa à célula mamária.

Silva et al. (2006), trabalhando com fontes lipídicas protegidas e não protegidas na dieta de cabras, verificaram redução na quantidade do C12:0 e do C14:0 em relação à dieta sem óleo. Mesquita et al. (2006) avaliaram a inclusão de feno de maniçoba (Manihot glaziovii Muel arg.) na dieta de cabras mestiças Moxotó e encontraram diferença $(\mathrm{P}<0,05)$ na concentração do $\mathrm{C} 14: 0(7,85 \%)$ quando fornecida a dieta com relação volumoso:concentrado 60:40, o que indica também que a relaçãovolumoso:concentrado pode alterar o perfil lipídico do leite de cabras.

A concentração de ácido palmítico foi maior quando fornecida a dieta com óleo de algodão, fonte rica em ácido palmítico, que reflete a relação entre a quantidade de ácido palmítico C16:0 ingerido na dieta e a quantidade desse ácido excretada no leite, ou seja, quanto maior a quantidade de ácido $\mathrm{C} 16: 0$ ingerida maior a quantidade excretada.

As concentrações dos ácidos esteárico (C18:0), oléico $(\mathrm{C} 18: 1)$ e linoléico $(\mathrm{C} 18: 2)$ aumentaram $(\mathrm{P}<0,05)$ com a inclusão dos óleos, bem como a quantidade de insaturados depositados no leite também se elevou $(\mathrm{P}<0,05)$, os quais podem ter diferentes origens. Os ácidos graxos insaturados podem alterar a fermentação ruminal da fibra pela ação tóxica sobre a população de bactérias fibrolíticas e estas bactérias, por sua vez, estão envolvidas no processo de biohidrogenação dos ácidos graxos poliinsaturados (Palmquist \& Jenkins, 1980).

Os resultados deste trabalho, no qual os teores de $\mathrm{C} 18: 2$ e $\mathrm{C} 18: 3$ aumentaram $(\mathrm{P}<0,05)$ com a adição de óleo na dieta, diferem dos relatos de Maia et al. (2006), que, em pesquisa com óleos de canola, arroz e soja na alimentação de cabras leiteiras, verificaram aumento $(\mathrm{P}<0,05)$ na concentração dos ácidos esteárico (C18:0) e oléico (C18:1), não sendo verificada $(\mathrm{P}>0,05)$ essa influência para os ácidos linoléico (C18:2) e linolênico(C18:3). A suplementação de dietas ricas em $\mathrm{C} 18: 3$ protegidas do ataque dos microrganismos ruminais pode ser uma alternativa interessante para aumentar a proporção do ácido linolênico (C18:3) no leite e a ingestão deste ácido graxo essencial pelo leite (Kitessa et al., 2001).

\section{Conclusões}

A adição de óleo em dietas para cabras mestiças Moxotó aumentou o teor de gordura do leite, tornando esse produto de maior rentabilidade para os laticínios. A adição de óleo na dieta diminuiu a quantidade de ácidos graxos de cadeia curta, como o mirístico, que pode proporcionar sérios problemas à saúde. O óleo de girassol a 5\% na MS aumentou a concentração de ácidos graxos poliinsaturados, principalmente o linolênico, que pode tornar o leite um produto melhor para o consumo humano, tendo em vista o provável efeito deste ácido graxo na prevenção de problemas cardiovasculares.

\section{Agradecimento}

À CAPES, pela bolsa de pesquisa. A Alexandre Cortês, pela ajuda na condução do projeto; a Ingrid Dantas, pelo apoio na realização das análises laboratoriais; e a Renata Ângela Guimarães, pela contribuição na revisão, elaboração e correções do projeto.

\section{Literatura Citada}

ARAÚJO, M.J. Feno de maniçoba (Manihot glaziovii Muell. Arg.) em dietas para cabras da raça Moxotó em lactação. Areia: Universidade Federal da Paraíba, 2005. 72p. Dissertação (Mestrado em Zootecnia) - Universidade Federal da Paraíba, 2005.

ASSOCIATION OF OFFICIAL ANALYTICAL CHEMISTS AOAC. Official methods of analysis. 16.ed. Arlington: AOAC International, 1998. 1170p.

BARROS, N.N.; SILVA, F.L.R.; ROGÉRIO, M.C.P. Efeito do genótipo sobre a produção e a composição do leite de cabras mestiças. Revista Brasileira de Zootecnia, v.34, n.4, p.1366$1370,2005$.

BATEMAN, H.G.; JENKINS, T.C. Influence of soybean oil in high fiber diets fed to no lactating cows on ruminal unsaturated fatty acids and nutrient digestibility. Journal of Dairy Science, v.81, p.2451-2458, 1998.

CANALE, C.J.; BURGESS, P.L.; MULLER, L.D. et al. Calcium salts of fatty acids in diets that differ in neutral detergent fiber: Effect on lactation performance and nutrient digestibility. Journal of Dairy Science, v.73, n.4, p.1031-1038, 1990.

CANT, J.P.; FREDEEN, A.H.; MacINTYRE, T. et al. Effect of fish oil on milk composition in dairy cows. Canadian Journal of Animal Science, v.77, p.125-131, 1997.

CHILLIARD, Y.; FERLAY, A.; ROUEL, J. et al. A review of nutritional and physiological factors affecting goat milk lipid synthesis and lipolysis. Journal of Dairy Science, v. 86, p.1751-1770, 2003.

CHURCH, D.C. The ruminant animal: digestive, physiology and nutrition. Englewood Ciffs: Simon \& Schuster, 1988. 543p.

DUARTE, L.M.A.; STUMPF JR., W.; FISCHER, V. et al. Efeito de diferentes fontes de gordura na dieta de vacas Jersey sobre o consumo, a produção e a composição do leite. Revista Brasileira de Zootecnia, v.34, n.6, p.2020-2028, 2005.

EIFERT, E.C.; LANA, R.P.; LANNA, D.P.D. et al. Efeitos do fornecimento de monesina e óleo de soja na dieta sobre o desempenho de vacas leiteiras na fase inicial da lactação. Revista Brasileira de Zootecnia, v.34, n.6, p.2123-2132, 2005.

GRANT, R.J.; WEIDNER, S.J. Effect of fat from whole soybeans on performance of dairy cows fed rations differing in fiber level and particle size. Journal of Dairy Science, v.75, n.10, p.2742-2751, 1992.

HARTMAN, L.; LAGO, R.C.A. Rapid preparation of fatty acid methyl esters from lipids. Laboratory Practice, v.22, p.475483, 1973.

HOF, G.; VERVOORN, M.D.; LENAERS, P.J. et al. Milk urea nitrogen as a tool to monitor the protein nutrition of dairy cows. Journal of Dairy Science, v.80, p.3333-3340, 1997. 
INSTITUO ADOLFO LUTZ - IAL. Normas analíticas do Instituto Adolfo Lutz. São Paulo: O Instituto, 2005. 1018p.

KITESSA, S.M.; GULATI, S.K.; ASHES, J.R. et al. Utilization of oil in ruminants. II. Transfer of fish oil fatty acids into goats' milk. Animal Feed Science and Technology, v.89, p.201-208, 2001.

KRONFELD, D.S. Major metabolic determinants of volume, mammary efficiency and spontaneous Ketosis in dairy cows. Journal of Dairy Science, v.65, n.11, p.2204, 1982

KRONFELD, D.S.; DONOGHUE, S.; NAYLOR, J.M. et al. Metabolic effects of feeding protected tallow to dairy cows. Journal of Dairy Science, v.63, n.4, p.545-552, 1980.

LAGUNA, L.E.; EGITO, A.S.; NUNES, R.G.F. Avaliação físicoquímica do leite de cabra de três rebanhos mestiços na região de Sobral, Ceará, Brasil. Revista do Instituto de Laticínios Cândido Tostes, v.53, n.304, p.153-157,1998.

LANA, R.P.; CAMARDELLI, M.M.L.; QUEIROZ, A.C. et al. Óleo de soja e própolis na alimentação de cabras leiteiras. Revista Brasileira de Zootecnia, v.34, n.2, p.650-658, 2005.

MAIA, F.J.; BRANCO, A.F.; MOURO, G.F. et al. Inclusão de fontes de óleo na dieta de cabras em lactação: produção, composição e perfil dos ácidos graxos do leite. Revista Brasileira de Zootecnia, v.35, n.4, p.1496-1503, 2006.

MESQUITA, I.V.U.; COSTA, R.G.; QUEIROGA, R.C.R.E. et al. Composição química do leite de cabras da raça Moxotó alimentadas com diferentes níveis de silagem de maniçoba (manihot Glaziovii muel arg.).In: REUNIÃO ANUAL DA SOCIEDADE BRASILEIRA DE ZOOTECNIA, 43.,2006, João Pessoa. Anais... João Pessoa: Sociedade Brasileira de Zootecnia, 2006. (CD-ROM).

MIR, Z.; GOONEWARDENE, L.A.; OKINE, E. et al. Effect of feeding canola oil on constituents, conjugated linoléico acid (CLA) and long chain fatty acids in goats milk. Small Ruminant Research, v.33, p.137-143, 1999.

MOURO, G.F.; BRANCO, A.F.; MACEDO, F.A.F. et al. Substituição do milho pela farinha de mandioca de varredura em dietas de cabras em lactação: fermentação ruminal e concentrações de uréia plasmática e no leite. Revista Brasileira de Zootecnia, v.31, n.4, p.1840-1848, 2002.

NATIONAL RESEARCH COUNCIL - NRC. Nutrient requirements of dairy cattle. 7.ed. Washington, D.C.: National Academy of Science, 2001. 381p.

NATIONAL RESERARCH COUNCIL - NRC. Nutrient requirements of dairy goats. Washington, D.C.: National Academy of Science, 1981. 110p.

PALMQUIST, D.L. Influence of source and amount of dietary fat on digestibility in lacting cows. Journal of Dairy Science, v.74, n.4, p.1351-1360, 1991.

PALMQUIST, D.L.; JENKINS, T.C. Fat in lactation rations: review. Journal of Dairy Science, v.63, n.1, p.1-14, 1980.
PARK, Y.W. Hypo-allergenic and therapeutic significance of goat milk. Small Ruminant Research, v.14, p.151-159, 1994.

PÉREZ, L.; SANZ SAMPELAYO, M.R.; GIL EXTREMERA, F. et al. Production of a more healthy goat milk. Use of diets supplemented with protected fat rich in PUFA. In: INTERNATIONAL SYMPOSIUM BASIS OF THE QUALITY OF TYPICAL MEDITERRANEAN ANIMAL PRODUCTS, 1996, Badajoz. Proceedings... Badajoz: 1996. p.203-208.

QUEIROGA, R.C.R.E; COSTA, R.G. Qualidade do leite caprino. In: SIMPÓSIO INTERNACIONAL DE CONSERVAÇÃO DE RECURSOS GENÉTICOS - Raças nativas para o semi-árido, 1., 2004, Recife. Anais... Recife: 2004. p.161-171.

QUEIROGA,R.CR. E. COSTA, R.G; BISCONTINI, T.M.B. et al. Influência do manejo do rebanho, das condições higiênicas da ordenha e da fase de lactação na composição química do leite de cabras Saanen. Revista Brasileira de Zootecnia, v.36, n.2, p.430-437, 2007.

SANTOS, F.L.; LANA, R.P.; SILVA, M.T.C. et al. Produção e composição do leite de vacas submetidas a dietas contendo diferentes níveis e formas de suplementação de lipídios. Revista Brasileira de Zootecnia, v.30, n.4, p.1376-1380, 2001.

SANZ SAMPELAYO, M.R.S.; CHILLIARD, Y.; SCHMIDELY, P. et al.Influence of type of diet on the fat constituents of goat and sheep milk. Small Ruminant Research, v.68, p.42-63, 2007.

SILVA, M.M.C.; RODRIGUES, M.T.; BRANCO, R.H. et al Suplementação de lipídios em dietas para cabras em lactação: consumo e eficiência de utilização de nutrientes. Revista Brasileira de Zootecnia, v.36, n.1, p.257-267, 2007.

SILVA, M. M.C.; RODRIGUES, M.T.; SILVA, M.T.C.S. et al. Perfil de ácidos graxos do leite de cabras recebendo suplementos de lipídios na dieta. In: REUNIÃO ANUAL DA SOCIEDADE BRASILEIRA DE ZOOTECNIA, 43., 2006, João Pessoa. Anais... João Pessoa: Sociedade Brasileira de Zootecnia, 2006. (CD-ROM).

STATISTICAL ANALISYS SYSTEM - SAS. SAS user's guide: statistics. version 6.2 Cary: 1996. (CD-ROM).

WU, Z.; HUBER, J.T. Relationship between dietary fat supplementation and milk protein concentration in lactating cows: a review. Livestock Prodution Science, v.39, n.2, p.141-155, 1994.

ZAMBOM, M.A.; CLAUdETE, R.A.; HASHIMOTO, J.H. et al. Produção e qualidade do leite de cabras Saanen recebendo rações com casca do grão de soja em substituição ao milho. In: REUNIÃO ANUAL DA SOCIEDADE BRASILEIRA DE ZOoteCniA, 43., 2006, João Pessoa. Anais... João Pessoa: Sociedade Brasileira de Zootecnia, 2006. (CD-ROM). 